\title{
Fístula broncobiliar entre un quiste hidatídico hepático y el lóbulo medio del pulmón derecho
}

\author{
J. Mª MORENO PLANAS, L. ABREU GARCÍA, J. C. MÉNDEZ CENDÓN*, \\ J. L. MARTÍNEZ PORRAS, F. PONS RENEDO, A. VARELA** \\ Servicio Aparato Digestivo. *Servicio Radiología. **Servicio Cirugía Torácica. Clínica \\ Puerta de Hierro. Madrid
}

\begin{abstract}
RESUMEN
Presentamos el caso de una fístula broncobiliar entre un quiste hidatídico localizado en el lóbulo derecho hepático y el lóbulo medio del pulmón derecho, localización poco frecuente de estos trayectos fistulosos. Dado lo poco habitual de esta patología revisamos su etiopatogenia, sintomatología, diagnóstico y tratamiento.
\end{abstract}

PALABRAS CLAVE: Fístula broncobiliar. Hidatidosis.
BRONCHOBILIARY FISTULOUS TRACT BETWEEN A LIVER HYDA TID CYST AND THE MIDDLE LOBE OF THE RIGHT LUNG

\author{
ABSTRACT \\ We report a case of bronchobiliary fistula between a liver hydatid \\ cyst and the middle lobe of the right lung. It is also reviewed the etiology, \\ pathogenesis, clinical features, diagnosis and treatment of bronchobi- \\ liary fistulas.
}

KEY WORDS: Bronchobiliary fistula. Hydatid disease.

Moreno Planas JMa, Abreu García L, Méndez Cendón JC, Martínez Porras JL, Pons Renedo F, Varela A. Fístula broncobiliar entre un quiste hidatídico hepático y el lóbulo medio del pulmón derecho. An Med Interna (Madrid) 2002; 19: 635-636.

\section{INTRODUCCIÓN}

La mayoría de las fístulas broncobiliares en pacientes con hidatidosis hepática ocurren entre un quiste localizado en el lóbulo hepático derecho y los segmentos basales del lóbulo pulmonar derecho. El segmento más comunmente afectado es el segmento basal posterior del lóbulo inferior derecho (1). En el caso que se presenta a continuación existe un trayecto fistuloso entre un quiste hidatídico localizado en el lóbulo hepático derecho y el lóbulo medio derecho.

\section{CASO APORTADO}

Mujer de 76 años remitida a la Unidad de Endoscopia Digestiva de la Clínica Puerta de Hierro para la realización de CPRE, ante la sospecha clínica de fístula broncobiliar. La paciente refería frecuentes episodios de tos con un esputo de coloración amarillenta (bilioptisis), disnea, dolor pleurítico derecho y fiebre las tres últimas semanas, que no habían mejorado con tratamiento antibiótico. No refería dolor abdominal, ictericia ni pérdida ponderal.

Como antecedentes personales presentaba una lobectomía derecha parcial por un quiste hidatídico 30 años antes. Estaba apendicectomizada, presentaba una bronconeumopatía crónica obstructiva, y había tenido una infección por anisakis un año antes. Estaba tomando ofloxacino y no refería alergias medicamentosas.

En el examen físico la paciente estaba bien nutrida y coloreada, con tensión arterial, frecuencia cardíaca y respiratoria normales y no tenía fiebre. Presentaba una disminución del murmullo vesicular en ambos campos pulmonares con una auscultación cardíaca normal. El abdomen era blando, doloroso a la palpación de epigastrio, sin signos de peritonismo, masas ni visceromegalias. El resto de la exploración fue normal.

La analítica reveló una leucocitosis $\left(13.600 / \mathrm{mm}^{3}\right)$, con un patrón bioquímico de colestasis con bilirrubinemia normal. La radiología pulmonar mostró bronquiectasias basales derechas y la TC toracoabdominal reveló bronquiectasias en el lóbulo medio derecho, un quiste hidatídico calcificado en el lóbulo hepático derecho y otro de menor tamaño en el lóbulo hepático izquierdo (Fig. 1). En la broncoscopia se visualizaron múltiples secrecciones biliosas provenientes del lóbulo medio derecho. Por último la CPRE mostró un trayecto fistuloso entre un quiste hidatídico localizado en el lóbulo derecho hepático y los segmentos basales del pulmón derecho (Fig. 2). Se realizó una esfinterotomía endoscópica, extrayéndose material hidatídico.

A la vista de las exploraciones complementarias, se decidió realizar una toracotomía derecha, visualizándose múltiples adherencias pleurales y un lóbulo medio atelectasiado, adherido al diafragma. Se realizó una extirpación del trayecto fistuloso y una lobectomía media. No se actuó sobre el quiste hidatídico porque se hallaba calcificado. Un año después de la cirugía la paciente se encuentra asintomática.

\section{DISCUSIÓN}

La hidatidosis, enfermedad causada por Echinococcus granulosus, puede aparecer en cualquier lugar del mundo, pero es más prevalente en aquellas áreas con importante gana-

Trabajo aceptado: 18 de septiembre de 2001

Correspondencia: J. Mª. Moreno Planas. Dionisio Guardiola, 15-3 F. 02003 Albacete. 


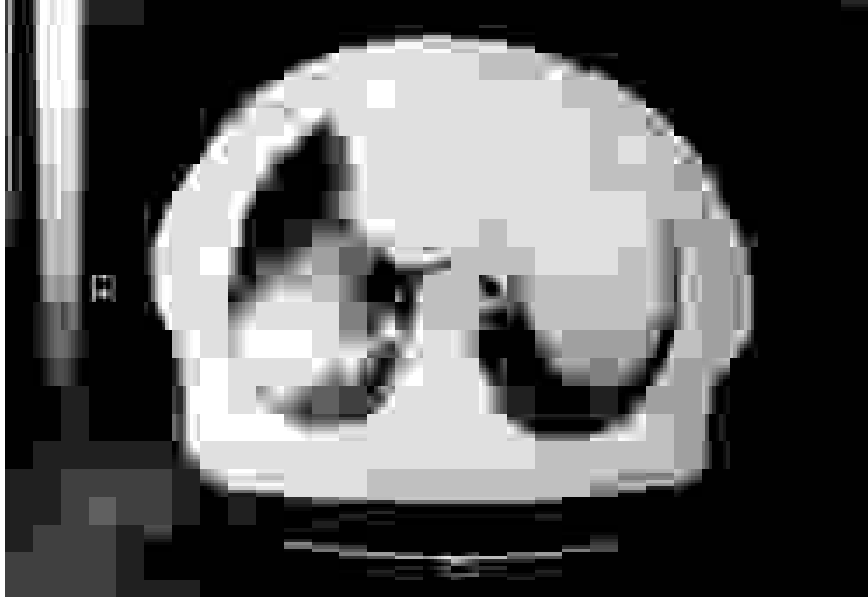

Fig. 1. Imagen de tac abdominal que muestra los dos quistes hidatídicos calcificados, uno en el lóbulo hepático derecho con aire en su interior, y bronquiectasias y engrosamiento de la pared bronquial en el lóbulo medio del pulmón derecho.

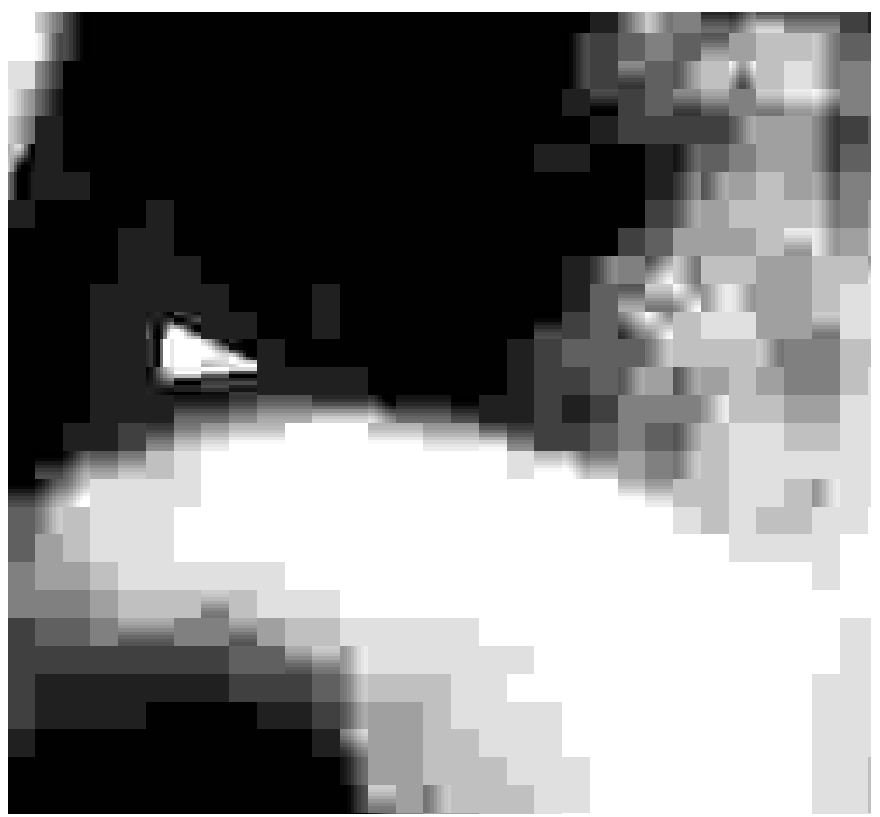

Fig. 2. Imagen de cpre mostrando el trayecto fistuloso entre un quiste hidatídico hepático, el árbol biliar y los segmentos basales del pulmón derecho.

do ovino. Los Echinococcus son gusanos que viven en el intestino de carnívoros, como perros, gatos, zorros y lobos, que constituyen sus huéspedes definitivos. Los seres humanos son huéspedes intermedios, al igual que las ovejas, cabras, cerdos y otros herbívoros; el hombre habitualmente se infecta al ingerir huevos de Echinococcus granulosus excretados en las heces por un huésped definitivo (en España fundamentalmente perro). Los órganos más frecuentemente afectados son el hígado (en el $70 \%$ de los casos) y el pulmón.

Una de las complicaciones más serias de la enfermedad hidatídica hepática es el desarrollo de un trayecto fistuloso entre un quiste hidatídico hepático y los segmentos basales pulmonares. La primera descripción de una fístula broncobiliar la realizó Peacock en 1.850 en un paciente con un quiste hidatídico (2). Esta variedad de fístulas puede ser de origen congénito o secundario a un traumatismo toracoabdominal, pero también pueden ocurrir como complicación de enfermedades del tracto biliar.

Trayectos fistulosos entre quistes hidatídicos hepáticos y un lóbulo pulmonar aparecen entre el 2 y el $21 \%$ de los pacientes con hidatidosis $(3,4)$. El factor etiológico más importante implicado es la infección del quiste tras su contacto con la vía biliar, debido a la obstrucción de ésta por hidátides o coledocolitiasis (5). Se produce posteriormente la formación de un absceso que erosiona el diafragma y la pleura y se abre en el árbol bronquial (6). Aparte de la infección del quiste y de la hipertensión biliar otros factores que predisponen a la ruptura y la formación de fístulas son el hecho de que la presión intratorácica es inferior que la intraabdominal, y la tendencia de la periquística a erosionar estructuras adyacentes (7). Las fístulas habitualmente se desarrollan entre un quiste hidatídico localizado en el lóbulo hepático derecho y los segmentos basales del pulmón derecho. El segmento pulmonar más frecuentemente afectado es el segmento basal posterior del lóbulo inferior derecho (7), siendo menos común la afectación del segmento basal anterior de dicho lóbulo y la del lóbulo medio, como ocurre en el caso que presentamos.

El diagnóstico de fístula broncobiliar se realiza clínicamente por la presencia de bilis en el esputo. Aunque los síntomas respiratorios, la ictericia y la colangitis son síntomas cardinales, la bilioptisis es patognomónica de esta condición. La broncoscopia y la broncografía raramente demuestran la fístula, y la CPRE, la CTPH y la TC pueden ser útiles en su detección (5).

Por último, el objetivo del tratamiento quirúrgico $(8,9)$ de la enfermedad hidatídica hepatopulmonar es la resolución de las complicaciones pulmonares, suturando el orificio diafragmático y resecando el quiste hidatídico. La hipertensión biliar debe ser diagnosticada y tratada antes de la corrección quirúrgica de la fístula, porque si no se resuelve es improbable que se mantenga la fístula cerrada tras la intervención. Habitualmente el tratamiento de elección es la esfinterotomía endoscópica.

\section{Bibliografía}

1. Boyd DP. Bronchobiliary and bronchopleural fistulas. Ann Thorac Surg 1977; $24:$ 481-7.

2. Peacock TB. Case in which hydatids were expectorated and one of suppuration of a hydatid cyst of the liver communicating with the lungs. Edinburg Med Surg J 1850; 74: 33-46.

3. Kourias B. Second World Congress of Gastroenterology, Munich, $1963 ; 556$.

4. Mzabi R, Bach K. Traitement des kystes hydatiques du foie ouverts dans bronches. Chirurgie 1978; 104 (5): 404-12.

5. Gugenheim J, Ciardullo M, Traynor O, Bismuth H. Bronchobiliary fis- tulas in adults. Ann Surg 1988; 207 (1): 90-4

6. Acea B, Fraguela J, Blanco B, Gómez C. Hidroneumoquiste, derrame pleural y bilioptisis. Rev Clin Esp 1997; 197: 65-7.

7. Borrie J, Shaw JHE. Hepatobronchial fistula caused by hydatid disease. The Dunedin Experience 1952-1979. Thorax 1981; 36: 25-8.

8. Gerazounis M, Atharassiadi K, Metaxas E, Athanassiou M, Kalarsi N. Bronchobiliary fistulae dueto echinocaccions. Eur J Cardiothorac Surg 2002; 22: 306-8.

9. Kabiri EH, El maslout A, Benosman A. Thoraui Nipture of hepaic hydatidons (123 cases). Ann Thorac Sueg 2001; 72: 1883-6. 